\title{
Aortic Dissection in a Survivor after Cardiopulmonary Resuscitation
}

\author{
Jeong-Sun Lee and Suk-Kyung Hong \\ Division of Trauma and Surgical Critical Care, Department of Surgery, Asan Medical Center, University of Ulsan College of Medicine, Seoul, Korea
}

\begin{abstract}
We describe a case of traumatic aortic dissection associated with cardiac compression in a patient with anaphylactic cardiac arrest who underwent cardiopulmonary resuscitation (CPR). A 54-year-old man who was scheduled to undergo surgery for gastric cancer went into cardiac arrest caused by an anaphylactic reaction to prophylactic antibiotics in the operating room. Veno-arterial extracorporeal membrane oxygenation (ECMO) was performed. CPR, including chest compressions, was performed for 35 minutes, and the patient was transferred to the intensive care unit (ICU) after spontaneous circulation returned. The patient received ECMO for 9 hours until confirmation of normal cardiac function on transthoracic echocardiography. Twenty days after cardiac arrest, an aortic dissection and fractures in the left fourth and fifth ribs due to chest compression were detected by abdominal computed tomography. The DeBakey type III aortic dissection extended from the distal arch of the thoracic aorta to the proximal level of the renal artery, involving the celiac trunk. It was considered an uncomplicated type B aortic dissection with no sign of malperfusion of the major vessels. This case demonstrates the potential traumatic injuries that can occur after CPR and encourages proper management of mechanical complications in cardiac arrest survivors.
\end{abstract}

Key Words: aortic dissection; cardiopulmonary resuscitation; computed tomography, spiral.

Cardiopulmonary resuscitation (CPR) is an inevitable procedure used to save lives during sudden cardiac arrest. However, mechanical resuscitation measures, such as chest compression, can result in resuscitation-related trauma such as thoracic injuries. Herein, we describe a case of traumatic aortic dissection associated with cardiac compression in a patient with anaphylactic cardiac arrest who survived after CPR with extracorporeal membrane oxygenation (ECMO) support.

\section{Case Report}

The patient was a 54-year-old man who was scheduled to undergo open subtotal gastrectomy for gastric cancer. He had no underlying diseases, except dyslipidemia, and no history of allergic responses to drugs. The patient was transferred to the operating room without any abnormal signs or symptoms. Midazolam (2 mg), lidocaine (20 mg), propofol

\author{
Received on May 9, 2016 Revised on May 30, 2016 Accepted on June 14, 2016 \\ Correspondence to: Suk-Kyung Hong, Division of Trauma and Surgical Critical Care, Department of Surgery, Asan Medical Center, 88 Olympic-ro 43-gil, Songpa-gu, \\ Seoul 05505, Korea \\ Tel: +82-2-3010-6515, Fax: +82-2-3010-6516, E-mail: skhong94@amc.seoul.kr \\ *No potential conflict of interest relevant to this article was reported.
}

(cc) This is an Open Access article distributed under the terms of the Creative Commons Attribution Non-Commercial License (http:/creativecommons.org/ licenses/by-nc/4.0/) which permits unrestricted non-commercial use, distribution, and reproduction in any medium, provided the original work is properly cited. Copyright (c) 2017 The Korean Society of Critical Care Medicine 

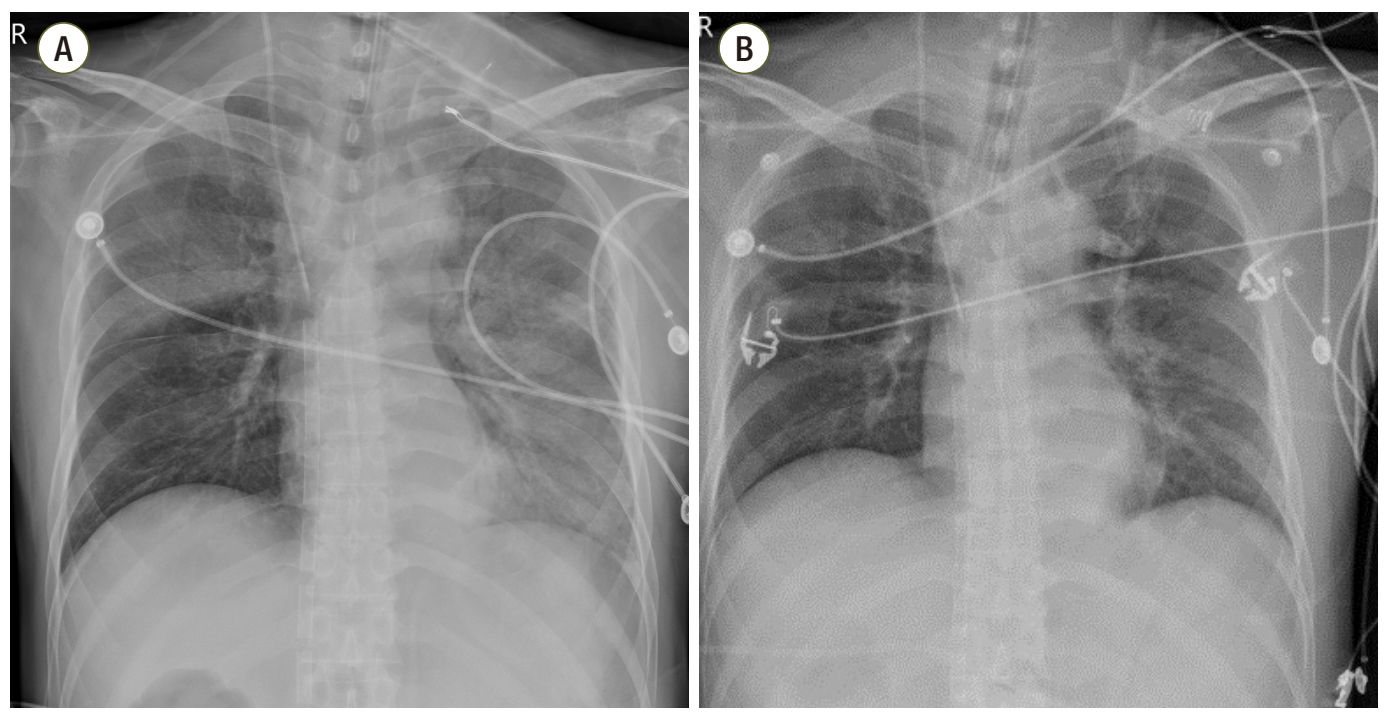

Figure 1. Anteroposterior chest radiography performed after cardiopulmonary resuscitation. (A) Initial chest radiography in the ICU shows diffuse pulmonary edema and subsegmental atelectasis in the left lower lung field. (B) Follow-up chest radiography performed after 6 hours reveals that pulmonary edema was improved due to the improvement in cardiac function. ICU: intensive care unit.

(60 $\mathrm{mg})$, and cisatracurium $(8 \mathrm{mg})$ were administered intravenously for induction of general anesthesia. After endotracheal intubation but before skin incision, $1 \mathrm{~g}$ cefotetan was administered intravenously as a prophylactic antibiotic. A few minutes later, the patient's heart rate suddenly dropped to less than 30 beats/min, according to electrocardiography monitoring, and he went into cardiac arrest. CPR was initiated immediately, and transesophageal echocardiography performed during CPR showed akinesia and low ejection fraction in the left ventricle. Because normal cardiac contractility was not recovered during CPR, veno-arterial ECMO was performed. The catheters for arterial inflow (catheter size, $15 \mathrm{Fr}$ ) and venous outflow (catheter size, $21 \mathrm{Fr}$ ) for ECMO were inserted through the right femoral artery and the left femoral vein, respectively. CPR including chest compressions was performed for 35 minutes. After return of spontaneous circulation, the patient's blood pressure was $110 / 60 \mathrm{mmHg}$, his pulse rate was 70 beats/min, and the level of lactic acid reached $12.1 \mathrm{mmol} / \mathrm{L}$. The patient was transferred to the intensive care unit (ICU) without performing the planned operation. His initial vital signs on admission to the ICU were 114/64 $\mathrm{mmHg}, 110$ beats/min, and a lactic acid level of $9.7 \mathrm{mmol} / \mathrm{L}$. Initial chest radiography in the ICU showed diffuse pulmonary edema and subsegmental atelectasis (Figure 1). Transthoracic echocardiography (TTE) performed on the day of ICU admission confirmed normal left and right ventricle contractility and 59\% ejection fraction. Repositioning of the ECMO catheter was considered to correct the malposition; however, ECMO was stopped after 9 hours due to confirmation of normal cardiac function on TTE. Mechanical ventilation was maintained for 18 days. Owing to persistent loss of renal function, renal replacement therapy was continued after recovery. Twenty days after his cardiac arrest, abdominal computed tomography (CT) was performed for re-evaluation and therapeutic planning of the remaining malignant gastric mass. The examination revealed left fourth and fifth rib fractures as well as an aortic dissection extending from the proximal descending thoracic aorta to the abdominal aorta; these findings were not observed on previous evaluations and were detected incidentally. The DeBakey type III aortic dissection extended from the distal arch of the thoracic aorta to the proximal level of the renal artery involving the celiac trunk (Figure 2). Twenty-five days after $\mathrm{CPR}$, the patient complained of atypical chest pain in the epigastric area, and angiographic CT and TTE were 

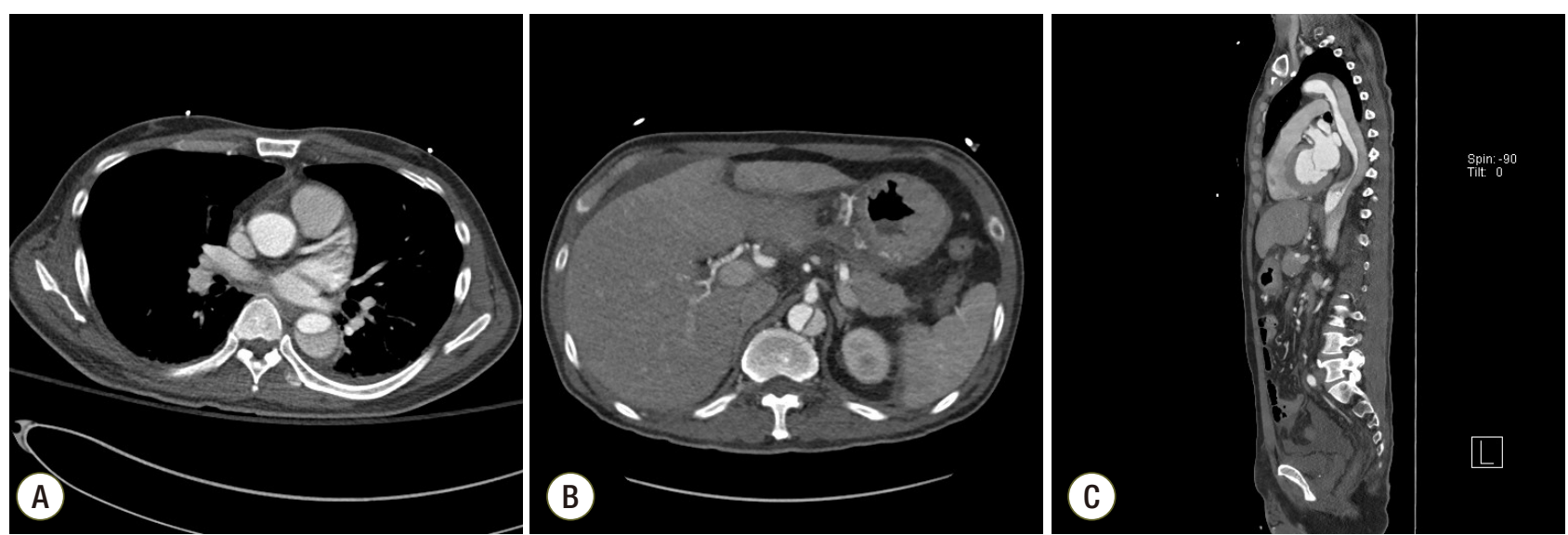

Figure 2. Aortic dissection after cardiopulmonary resuscitation. (A) Transverse contrast-enhanced computed tomography (CT) image shows dissection and saccular aneurysm of the proximal descending aorta and associated fracture of the left rib. (B) Transverse view at the abdominal level shows aortic dissection involvement of the celiac trunk; however, there is no malperfusion of the peripheral organs and periaortic hematoma. (C) Sagittal view of the contrast-enhanced CT image shows that the aortic dissection extends from the distal arch of the thoracic aorta to the proximal level of the renal artery.

performed to evaluate the extent of the aortic dissection and associated complications compared with the previous abdominal CT scan. Because there were no interval changes, it was considered an uncomplicated type B aortic dissection with no sign of malperfusion of the major vessels. Medical treatment including antihypertensive drugs was continued. One month later, the patient was diagnosed with an anaphylactic reaction to cefotetan based on a positive response to a skin prick test.

\section{Discussion}

CPR is a critical procedure for saving patients experiencing cardiac arrest by maintaining auxiliary cardiac circulation and ventilation until return of spontaneous cardiac circulation. In 1960, Kouwenhoven et al. [1] developed a method of external cardiac massage without thoracotomy for patients in cardiac arrest. Approximately 200,000 cases of in-hospital cardiac arrest occur each year in the United States [2]. The rate of survival to discharge is an estimated $15 \%$ to $20 \%[3,4]$. The survival rate after in-hospital cardiac arrest has improved steadily owing to quality improvement efforts [4]. In addition, several studies have suggested that ECMO during CPR has improved the survival rates of in-hospital cardiac arrest [5-7]. Along with increased survival after CPR, there has been a corresponding increase in concern about CPRrelated complications in survivors of cardiac arrest.

Resuscitation measures include invasive manipulations such as external cardiac compression, endotracheal intubation, and electric impulses for defibrillation. These manipulations support recovery of spontaneous circulation and termination of CPR, but patients may also experience traumatic injuries due to mechanical chest compression. In a study of approximately 1,000 autopsy cases, resuscitation-related injuries were reported in an estimated $21 \%$ to $65 \%$ of cases [8]. The most common complications after CPR are thoracic skeletal injuries, particularly fractures of the ribs (13\% to $97 \%$ ) and sternum (1\% to $43 \%)$ [9]. Fractured ribs can cause mediastinal hematoma, hemothorax, pneumothorax, and pulmonarycontusion [10]. Direct cardiac laceration and great vessel injuries are relatively rare but can lead to death [8].

Aortic dissection after CPR has rarely been reported in survivors [11-13]. Most blunt aortic injuries occur in the proximal descending aorta, where the relatively mobile aortic arch joins the fixed descending aorta via the ligamentum arteriosum. The shearing forces of sudden deceleration that occur in motor vehicle collisions can cause 
traumatic aortic dissection. Other mechanisms for this injury include sudden elevated intraluminal aortic pressure due to compression between the sternum and thoracic vertebrae [14]. The symptoms, clinical signs, and physical examination findings are nonspecific and difficult to differentiate from aortic dissection after CPR. A majority of CPR survivors cannot complain of symptoms because of decreased mentality due to hypoxic brain damage or a sedated state for post-CPR management, including mechanical ventilation. In these cases, the first clinical sign may be the onset of hemodynamic instability.

Chest radiography is typically used for screening, but it has a low sensitivity for diagnosing traumatic aortic injuries. Aortic injury after CPR may be suspected when chest radiography findings suggest mediastinal widening, loss of the aortopulmonary window, rightward tracheal/ nasogastric tube deviation, left main stem bronchus depression, and left apical cap [15]. Imaging studies useful for diagnosis include CT and transesophageal echocardiography (TEE). Chest $\mathrm{CT}$ has high diagnostic sensitivity, exceeding $97 \%$ to $100 \%$ for aortic dissection [16]. Chest CT can also be used to evaluate other associated damage, such as thoracic skeletal injuries and lung parenchymal injuries. TEE can be performed at bedside in patients with hemodynamic instability to evaluate the myocardium for wall motion abnormalities. However, TEE has limitations such as dependency on operator skill and poor visualization of the distal ascending aorta and proximal arch [17].

Aortic dissection after CPR is rare but can be fatal. In the absence of previous evaluation, it can also be difficult to confirm a causal relationship between CPR-induced injury and the underlying disease that caused the sudden cardiac arrest. The 2010 American Heart Association guidelines recommend harder (a depth of at least $5 \mathrm{~cm}$ ) and faster compressions (a rate of at least 100 compressions per minute) than the 2005 guidelines [18]. Increasing the requirements of compression depth and rate may increase the risk of CPR-related complications, including life-threatening events. Still, to prevent complications, chest compressions should be performed correctly and in the accurate position rather than reducing compressive efforts [19]. With increasing rates of survival with CPR, potential traumatic injuries caused by chest compression should be considered. Accurate diagnosis and proper treatment of unavoidable CPR-related complications are important to decrease traumatic damages.

ORCID

Suk-Kyung Hong http://orcid.org/0000-0001-5698-0122

\section{References}

1. Kouwenhoven, WB, Jude JR, Knickerbocker GG. Closed-chest cardiac massage. JAMA 1960;173: 1064-7.

2. Merchant RM, Yang L, Becker LB, Berg RA, Nadkarni V, Nivhol G, et al. Incidence of treated cardiac arrest in hospitalized patients in the United States. Crit Care Med 2011;39:2401-6.

3. Sandroni C, Nolan J, Cavallaro F, Antonelli M. Inhospital cardiac arrest: incidence, prognosis and possible measures to improve survival. Intensive Care Med 2007;33:237-45.

4. Girotra S, Nallamothu BK, Spertus JA, Li Y, Krumholz HM, Chan PS, et al. Trends in survival after in-hospital cardiac arrest. N Engl J Med 2012:367:1912-20.

5. Chen YS, Lin JW, Yu HY, Ko WJ, Jerng JS, Chang WT, et al. Cardiopulmonary resuscitation with assisted extracorporeal life-support versus conventional cardiopulmonary resuscitation in adults with in-hospital cardiac arrest: an observational study and propensity analysis. Lancet 2008;372:554-61 .

6. Chung SY, Sheu JJ, Lin YJ, Sun CK, Chang LT, Chen YL, et al. Outcome of patients with profound cardiogenic shock after cardiopulmonary resuscitation and prompt extracorporeal membrane oxygenation support: a single-center observational study. Circ J 2012;76:1385-92. 
7. Wu MY, Lee MY, Lin CC, Chang YS, Tsai FC, Lin PJ. Resuscitation of non-postcardiotomy cardiogenic shock or cardiac arrest with extracorporeal life support: the role of bridging to intervention. Resuscitation 2012;83:976-81.

8. Buschmann CT, Tsokos M. Frequent and rare complications of resuscitation attempts. Intensive Care Med 2009;35:397-404.

9. Hoke RS, Chamberlain D. Skeletal chest injuries secondary to cardiopulmonary resuscitation. Resuscitation 2004;63:327-38.

10. Sokolove PE, Willis-Shore J, Panacek EA. Exsanguination due to right ventricular rupture during closedchest cardiopulmonary resuscitation. J Emerg Med 2002;23:161-4.

11. Fagnoul, D, Herpain A, Vincent JL, De Backer D. Aortic luminal thrombus and intramural hematoma after cardiopulmonary resuscitation. Rev Bras Ter Intensiva 2013;25:345-7.

12. Oren-Grinberg A, Shahul S, Sarge T. Dissection of the thoracic aorta following cardiopulmonary resuscitation. Crit Ultrasound J 2011;3:25-7.

13. Univers J, Stevens S, Daley B. Aortic dissection after cardiopulmonary resuscitation. Am Surg 2015;81: E218-9.
14. Parmley LF, Mattinglly TW, Manion WC, Jahnke EJ Jr. Nonpenetrating traumatic injury of the aorta. Circulation 1958;17:1086-101.

15. Fabian TC, Davis KA, Gavant ML, Croce MA, Melton SM, Patton JH Jr, et al. Prospective study of blunt aortic injury: Multicenter Trial of the American Association for the Surgery of Trauma. J Trauma 1997;42:374-80.

16. Fabian TC, Davis KA, Gavant ML, Croce MA, Melton SM, Patton JH Jr, et al. Prospective study of blunt aortic injury: helical CT is diagnostic and antihypertensive therapy reduces rupture. Ann Surg 1998;227:666-76.

17. Konstadt SN, Reich DL, Quintana C, Levy M. The ascending aorta: how much does transesophageal echocardiography see? Anesth Analg 1994;78:240-4.

18. Berg RA, Hemphill R, Abella BS, Aufderheide TP, Cave DM, Hazinski MF, et al. Part 5: adult basic life support. 2010 American Heart Association Guidelines for Cardiopulmonary Resuscitation and Emergency Cardiovascular Care. Circulation 2010;122(18 Suppl 3):S685-705.

19. Krischer JP, Fine EG, Davis JH, Nagel EL. Complications of cardiac resuscitation. Chest 1987;92:287-91. 